\title{
Mental Rehearsal Strategy for Stress Management and Performance in Simulations
}

Citation for published version (APA):

Ignacio, J., Scherpbier, A., Dolmans, D., Rethans, J-J., \& Liaw, S. Y. (2017). Mental Rehearsal Strategy for Stress Management and Performance in Simulations. Clinical Simulation in Nursing, 13(7), 295-302. https://doi.org/10.1016/j.ecns.2017.04.005

Document status and date:

Published: 01/07/2017

DOI:

10.1016/j.ecns.2017.04.005

Document Version:

Publisher's PDF, also known as Version of record

Document license:

Taverne

Please check the document version of this publication:

- A submitted manuscript is the version of the article upon submission and before peer-review. There can be important differences between the submitted version and the official published version of record.

People interested in the research are advised to contact the author for the final version of the publication, or visit the DOI to the publisher's website.

- The final author version and the galley proof are versions of the publication after peer review.

- The final published version features the final layout of the paper including the volume, issue and page numbers.

Link to publication

\footnotetext{
General rights rights.

- You may freely distribute the URL identifying the publication in the public portal. please follow below link for the End User Agreement:

www.umlib.nl/taverne-license

Take down policy

If you believe that this document breaches copyright please contact us at:

repository@maastrichtuniversity.nl

providing details and we will investigate your claim.
}

Copyright and moral rights for the publications made accessible in the public portal are retained by the authors and/or other copyright owners and it is a condition of accessing publications that users recognise and abide by the legal requirements associated with these

- Users may download and print one copy of any publication from the public portal for the purpose of private study or research.

- You may not further distribute the material or use it for any profit-making activity or commercial gain

If the publication is distributed under the terms of Article $25 \mathrm{fa}$ of the Dutch Copyright Act, indicated by the "Taverne" license above, 


\title{
Mental Rehearsal Strategy for Stress Management and Performance in Simulations
}

\author{
Jeanette Ignacio, $M D, \mathrm{PhD}^{\mathrm{a}, *}$, Albert Scherpbier, $\mathrm{MD}, \mathrm{PhD}^{\mathrm{b}}$, \\ Diana Dolmans, MSc, $\mathrm{PhD}^{\mathrm{C}}$, Jan-Joost Rethans, MD, $\mathrm{PhD}^{\mathrm{C}}$, \\ Sok Ying Liaw, MHS (Ed), PhD ${ }^{d}$
}

${ }^{a}$ Senior Lecturer, Alice Lee Centre for Nursing Studies, Yong Loo Lin School of Medicine, National University of Singapore, Level 2, Clinical Research Centre, Singapore 117597, Singapore

${ }^{b}$ Professor and Dean, Faculty of Health, Medicine and Life Sciences, Maastricht University, 6200 MD, Maastricht, Netherlands

${ }^{c}$ Professor, Faculty of Health, Medicine and Life Sciences, Maastricht University, 6200 MD, Maastricht, Netherlands

${ }^{d}$ Assistant Professor, Alice Lee Centre for Nursing Studies, Yong Loo Lin School of Medicine, National University of

Singapore, Level 2, Clinical Research Centre, Singapore 117597, Singapore

\section{KEYWORDS \\ nursing education; psychological stress; simulation training; anxiety; mental rehearsal; performance}

\begin{abstract}
Background: A mental rehearsal (MR) strategy using standardized patients was implemented for third-year nursing students in a simulation training on clinical deterioration. The study aimed to evaluate its efficacy, by comparing with a conventional approach using a mnemonic strategy with mannequin simulation, for improving the nursing students' performance and reducing their stress level in patient deterioration management. The study also explored the students' perspectives of using MR during their clinical practice.

Method: A mixed methods design was used. Thirty-two third-year nursing students participated in a randomized posttest. They were assigned to either the MR group or mnemonic group. Performance was observed and measured using simulation-based assessment. Strait-Trait Anxiety Inventory, heart rate, systolic blood pressure, and skin temperature were used as stress measures. Twenty-one students participated in individual interviews after a nine-week clinical posting.

Results: Performance between the MR group and the mnemonic group $(p=.105)$ did not differ. The state $(p=.524)$ and trait $(p=.516)$ anxiety inventory, systolic blood pressure $(p=.890)$, heart rate $(p=.692)$, and skin temperature $(p=.521)$ did not differ between the two groups. Three themes were generated from the application of MR on students' clinical practice: being mentally and emotionally prepared, recalling and visualizing the steps to be taken, and enhancing actual clinical practice.

Conclusions: Both MR and the mnemonic strategies had similar effects on performance and stress during patient deterioration management. However, the interviews suggested that MR still benefits learning and has value in health professions' training.

Cite this article:

Ignacio, J., Scherpbier, A., Dolmans, D., Rethans, J.-J., \& Liaw, S. Y. (2017, July). Mental rehearsal strategy for stress management and performance in simulations. Clinical Simulation in Nursing, 13(7), 295-302. http://dx.doi.org/10.1016/j.ecns.2017.04.005.
\end{abstract}

(C) 2017 International Nursing Association for Clinical Simulation and Learning. Published by Elsevier Inc. All rights reserved.

\footnotetext{
* Corresponding author. nurimjj@nus.edu.sg (J. Ignacio).
} 


\section{Background}

It is vital for health care professionals to deliver safe and quality care to patients, and one of the methods by which professionals are trained is through simulations. Simulations

\section{Key Points}

- The use of a MR strategy with SPs and ABCDE mnemonics and mannequins were used in patient deterioration simulations.

- The MR strategy and the ABCDE mnemonic had similar effects in terms of improving performance and reducing stress levels of students.

- Qualitative results suggest that the MR strategy has been perceived by students as a valuable tool to prepare them for clinical practice.

provide a conducive and nonthreatening environment where technical skills can be practiced to enhance performance. Clinical performance, however, can be affected by factors other than technical skills. One of these factors is stress. Stress in a clinical setting can affect a health care professional's ability to analyze clinical situations, make decisions, and perform certain clinical procedures (LeBlanc, 2009). Nurses, being involved in direct patient care and the monitoring of patients, are frequently exposed to highly stressful and critical clinical events (Liaw, Scherpbier, Klainin-Yobas, \& Rethans, 2011b). Hence, it is important that the nursing curriculum integrates into its simulation program a strategy that provides emotional training, such as stress management, in high-acuity situations (Harvey, Nathens, Bandiera, \& LeBlanc, 2010; Liaw, Chan, Scherpbier, Rethans, \& Pua, 2012).

One of the techniques that has shown to be of benefit in training in various fields is mental rehearsal (MR). MR is a cognitive strategy that involves practicing skills without any actual physical movement (Driskell, Copper, \& Moran, 1994; Jones \& Stuth, 1997). The value of this strategy has been recognized primarily in sports wherein it has been successfully used in performance training of athletes (Aoun, Batjer, Rezai, \& Bendok, 2011; Cocks, Moulton, Luu, \& Cil, 2014). In health care training, MR is a relatively new strategy that has been used mostly by surgeons to train for certain procedures, such as laparoscopic surgery, prior to engaging in simulations (Aoun et al., 2011; Eldred-Evans et al., 2013), and more recently, by student nurses to assess and manage patient deterioration (Ignacio et al., 2016). Using such a strategy, alone or as an integral component of a stress management program, was effective in decreasing stress and improving performance in a group of inexperienced surgeons (Arora et al., 2011; Wetzel et al., 2011). Furthermore, MR has been shown as a form of stress inoculation that helps trainees manage their own stress (Arora et al., 2011).

The use of standardized patients (SPs) in simulation has shown much potential in improving performance and reducing stress in patient deterioration simulations (Ignacio et al., 2015). Although the quantitative results of a mixed methods study were not significant, students' perceptions on the use of SPs were very positive (Ignacio et al., 2015). Meanwhile, the potential benefits of the MR strategy to enhance performance and reduce stress in assessing and managing simulated patient deterioration have been previously demonstrated using pre- and posttest combined with focus group interviews (Ignacio et al., 2016). The evidence, however, may be limited as the MR strategy was not compared with another strategy used in simulation that has already been shown to be effective. The use of the Airway, Breathing, Circulation, Disability, Exposure (ABCDE) mnemonic is the conventional strategy used to teach nursing students how to assess and manage deteriorating patients. This strategy is used with simulations utilizing high-fidelity mannequins and was shown to benefit performance (Liaw, Rethans, Scherpbier, \& Klainin-Yobas, 2011a). To determine, therefore, whether the MR strategy really enhances performance, this study aimed to compare the immediate effects of the MR strategy with the conventional strategy on performance and stress in simulated patient deterioration scenarios, one with SPs and the other with mannequins. The study also aimed to determine the usefulness of the MR strategy in actual clinical settings.

\section{Methods}

\section{Study Design and Participants}

A mixed methods study comprising a randomized posttest design and a qualitative interview was conducted. The combination of quantitative and qualitative methods was used as this can moderate the limitations and leverage on the combined strengths of each individual approach (Johnson \& Onwuegbuzie, 2004).

On ethics approval from the university's institutional review board, all third-year nursing students $(n=93)$ enrolled in a clinical decision-making module in a university in Singapore were invited to join the study. A total of 33 students consented to participate. Using a computergenerated randomizer, 17 students were randomized to the intervention group (MR-SP), and 16 students were placed in the control group (MM). The 32 participants who completed this quantitative study component were invited to participate in individual interviews conducted after their nine-week clinical posting. Twenty-one students agreed to join. 


\section{Study Intervention}

The intervention consisted of an MR strategy that was developed and previously tested on a group of final year nursing students (Ignacio et al., 2016). The control, meanwhile, consisted of the conventional method in which students were taught to manage deteriorating patients by using the ABCDE mnemonic and exposure to patient deterioration simulation using mannequins. Figure 1 represents the details of the MR strategy and the conventional strategy.

The MR-SP and MM groups then underwent a posttest deteriorating patient simulation. SPs were used in the posttest simulations because they approximate the reality of a patient encounter. Meanwhile, the qualitative component of the study consisted of 45 to 60 minutes individual interviews.

\section{Data Collection and Outcome Measures}

Figure 2 illustrates the flow of the data collection. The demographic data, which included age, gender, and ethnicity, were collected from all participants. Performance and stress measures were done on both the MR-SP and MM groups during the posttest to determine the effectiveness of the MR strategy. The participants' performances were rated by the faculty staff who were familiar with deteriorating patient simulations and who had been trained with the use of the Rescuing a Deteriorating Patient in Deteriorating Situations (RAPIDS) tool. The raters were blinded to the identities of the participants as each participant wore a cap, a gown and a mask during the posttest simulation.

The individual interviews were conducted after the participants' nine-week clinical posting, five months after they had the intervention. These interviews were facilitated by a member of the research team who was experienced with this task.
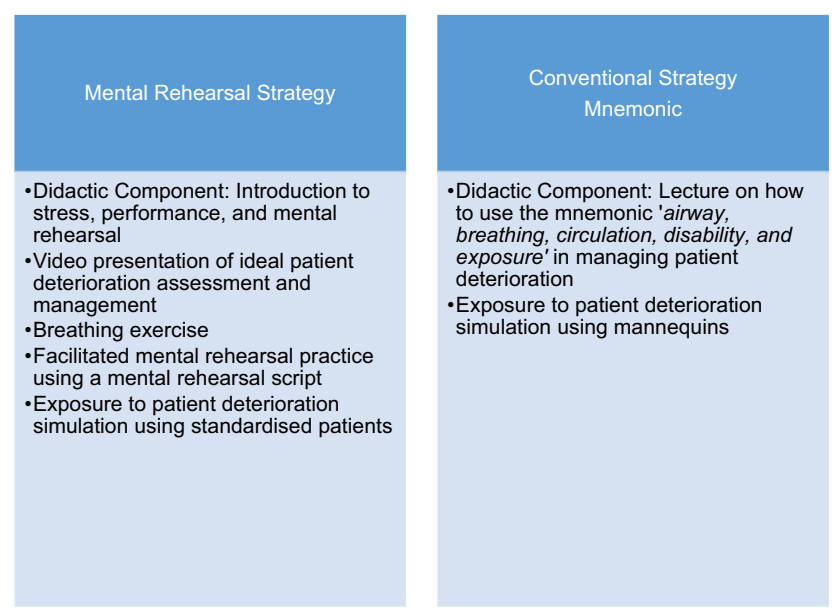

Figure 1 The mental rehearsal strategy and the conventional strategy.

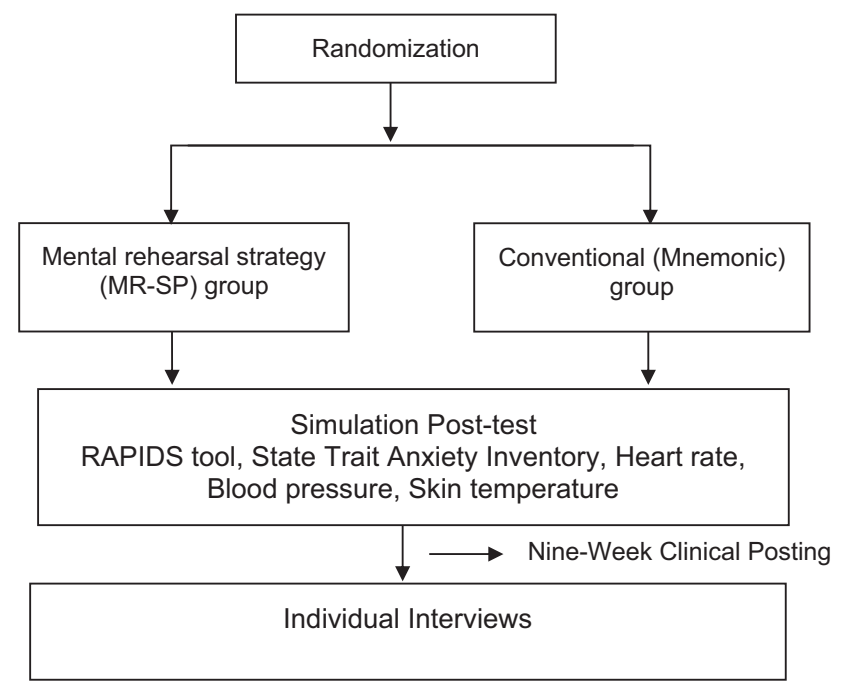

Figure 2 Flowchart of the study.

\section{Performance}

Performance was measured using the RAPIDS tool. The RAPIDS tool is a valid and reliable instrument (intraclass correlation $=0.99$ ) that consists of checklists and global rating scales that measure the simulation and clinical performance of nurses as they assess, manage, and report patient deterioration (Liaw, Scherpbier, Klainin-Yobas, \& Rethans, 2011b).

\section{Stress Levels}

Stress was measured using the Strait-Trait Anxiety Inventory that has an acceptable reliability and validity in research settings (Vitasari, Wahab, Othman, Herawan, \& Sinnadurai, 2011). This instrument consists of separate measures for state and trait anxiety. The 20-item state anxiety measures the anxiety felt by the respondent at that particular moment of time when he/she is answering the Strait-Trait Anxiety Inventory, whereas the 20-item trait anxiety measures how anxiety is generally perceived by the respondent (Spielberger, Gorsuch, Lushene, Vagg \& Jacobs, 1983). Physiologic determinants of stress such as heart rate, blood pressure, and skin temperature were also measured. An increase in heart rate and blood pressure due to catecholamine release is an expected result of the activation of the sympathetic adrenal medullary axis after stress exposure (Huang, Webb, Zourdos, \& Acevedo, 2013). Skin surface temperature is decreased during sympathetic response as the blood supply is enhanced to vital organs (Hjemdahl, 2000).

\section{Perceived Application of Learning}

An interview guide was used (see Table 1) to explore the participants' experiences with patient deterioration during their clinical posting and the practical application of the 


\begin{tabular}{l} 
Table 1 Guide Questions for the Individual Interview \\
Interview Guide Questions \\
\hline 1. During your nine-week posting, did you experience \\
attending to a deteriorating patient? (Can you tell me \\
more about it?) \\
2. Were you able to recall the steps that you needed to carry \\
out to adequately assess and manage the patient? (Were \\
you alone?) \\
3. How did you feel during the experience and what were \\
your thoughts then? \\
4. Do you think that the mental rehearsal strategy that we \\
introduced to you was actually helpful? Why do you \\
think so? \\
5. Any additional comments you want to give?
\end{tabular}

MR strategy in the clinical setting. The interviews were audio-recorded and transcribed.

\section{Data Analysis}

The data gathered from the randomized posttest component was analyzed using descriptive statistics. An independent $t$-test was used to compare the posttest outcome measures between the MR-SP group and the MM group. Audio-recorded individual interviews were transcribed verbatim, and thematic analysis was used to make sense of, and find the meaning in the participants' experiences (Braun \& Clarke, 2006). Credibility, confirmability, dependability, and transferability were maintained to ensure the rigor of the qualitative data analysis (Polit \& Beck, 2006). An audio-recording of each interview and member-checking for accuracy by a summary at the end of each interview ensured credibility and dependability. Confirmability was safeguarded after two researchers independently analyzed the interview scripts before coming together to generate the final themes. The applicability of the findings to clinical settings from the generated data was assessed to demonstrate transferability.

\section{Results}

\section{Participant Demographics}

A total of 32 final year nursing students completed the randomized posttest component of the study. Most of the participants were Chinese (75\%), female (84.4\%), have a mean age of 21.69 years, and who have completed junior college education (84.4\%) prior to attending university (Table 2).

\section{Performance}

There was no difference between the performance of the MR-SP group and the MM group using the RAPIDS tool

\begin{tabular}{lc}
$\begin{array}{l}\text { Table } 2 \\
(n=32)\end{array}$ & Demographic Characteristics of the \\
\hline $\begin{array}{l}n={ }^{2} \\
\text { Demographic Characteristics }\end{array}$ & Mean (SD) \\
\hline Age (years) & $21.69(1.230)$ \\
\hline & Total (\%) \\
\hline Gender & \\
Male & $5(15.6)$ \\
Female & $27(84.4)$ \\
Ethnicity & \\
Chinese & $24(75.0)$ \\
Malay & $3(9.4)$ \\
Indian & $5(15.6)$ \\
Others & $0(0)$ \\
Education & \\
Polytechnic & $5(15.6)$ \\
Junior college & $27(84.4)$ \\
\hline
\end{tabular}

during the posttest $(p=.105)$. This suggests that participants from the MR-SP group had the same performance skills as those from the MM group after going through the MR strategy. The results for performance are presented in Table 3.

\section{Stress Levels}

The posttest stress levels of the participants from the MRSP group did not significantly differ from those in the MM group. This was evidenced by the physiologic measures of stress such as systolic blood pressure $(p=.890)$, heart rate $(p=.692)$, and skin temperature $(p=.521)$. The state $(p=.524)$ and trait $(p=.516)$ anxiety inventory results also did not differ between the two groups. Table 4 shows the stress level results for the different measures used.

\section{Individual Interviews}

Twenty-one students who participated in the randomized posttest component of the study were individually interviewed. Three themes emerged from the application of MR during the students' clinical practice: (a) being mentally and emotionally prepared, (b) recalling and visualizing the steps to be taken, and (c) enhancing actual clinical practice.

\begin{tabular}{|c|c|c|c|}
\hline & $\begin{array}{l}\text { MR-SP Group } \\
(\mathrm{n}=17)\end{array}$ & $\begin{array}{l}\text { MM Group } \\
(n=15)\end{array}$ & \\
\hline Outcome Measure & $M(S D)$ & $M(S D)$ & $t$ \\
\hline $\begin{array}{l}\text { RAPIDS tool } \\
\text { scores }\end{array}$ & $67.88(11.42)$ & $62.13(7.27)$ & 1.672 \\
\hline
\end{tabular}

Note. $\mathrm{MM}=$ mnemonic; $\mathrm{MR}=$ mental rehearsal; RAPIDS = Rescuing a Deteriorating Patient in Deteriorating Situations; SP = standardized patient. 


\begin{tabular}{|c|c|c|c|}
\hline Outcome & $\begin{array}{l}\text { MR-SP Group } \\
(\mathrm{n}=17)\end{array}$ & $\begin{array}{l}\text { MM Group } \\
(\mathrm{n}=15)\end{array}$ & \\
\hline Measures & $M(S D)$ & $M(S D)$ & $t$ \\
\hline $\begin{array}{l}\text { Systolic blood } \\
\text { pressure }\end{array}$ & $118.06(10.89)$ & $117.47(13.098)$ & 0.140 \\
\hline Heart rate & 85.94 (19.57) & $83.73(19.572)$ & 0.401 \\
\hline Skin temperature & $27.83(3.02)$ & $27.18(2.57)$ & 0.650 \\
\hline State anxiety & $36.82(9.66)$ & 39.07 (9.989) & -0.645 \\
\hline Trait anxiety & $39.06(9.57)$ & $41.20(8.419)$ & -0.658 \\
\hline
\end{tabular}

\section{Being Mentally and Emotionally Prepared}

Good preparation has been mentioned by some of the participants as essential in managing acute clinical events such as patient deterioration. Mental preparation is one form of preparation that equips students to manage similar clinical incidents. In fact, one participant mentioned:

I think having a good mental preparation is very good for us before we perform any procedure .... We really need to prepare the patient and prepare ourselves, and mental rehearsal plays an important role in preparing ourselves. (P1)

The mental preparedness also has been perceived by some of the participants to promote the mitigation of stress as after practicing it, they know better what to do and thus become less stressed. An example of what some of the participants mentioned is as follows:

I think most of the time stress comes from not knowing what to do in a stressful situation. Yeah, so when you know you have something to do then it eliminates that part of the stress where you feel "Oh no, what am I supposed to do now?" (P5)

\section{Recalling and Visualizing the Steps to Be Taken}

Most of the participants commented that MR made it easier for them to recall certain information that they needed in order to perform well. Some felt that the integration of a storyline founded on the ABCDE mnemonic in the MR script helped visualize and recall the steps better. In fact, one participant noted:

It puts the scenario in a storyline rather than just using the ABCDE, (it's) easier to visualize .... With more practice using it, I got more familiar with the $\mathrm{ABCDE}$ and clinically, it is important. (P3)

MR has also been seen as a retrieval tool that helps in terms of remembering stored information or previous knowledge. For instance, one participant mentioned:
... it's like a retrieval tool .... You must have knowledge before, then with the mental rehearsal, you can use it to draw out the information that you have or you know. (P17)

\section{Enhancing Actual Clinical Practice}

The use of the MR strategy has been perceived by the majority of the participants to facilitate in learning by bridging the gaps that exist between what they learn in school and what they are expected to do in an actual clinical setting. One participant said:

Because in the ward, I think the source of our nervousness is our lack of knowledge and also lack of practice and everything. So with the mental rehearsal, I think you can bridge a bit of the gap. (P18)

As MR facilitates learning by integrating various information or knowledge acquired during training, it has to be practiced often. In fact, one participant suggested:

... implement it more frequently ... because I really

think it's something we should practice, practice more so we can use it like it's at the tip of our fingers ... (P12)

Interestingly, the use of the MR strategy has been perceived by some as a means to reflect on their learning such that they first practice MR, apply it to an actual event, and then modify their own MR to improve subsequent performances. For example, one participant noted:

You get to think about what you could have done, what you should have done better, and then rehearse all the different steps so that you can be prepared for another similar case. (P6)

\section{Discussion}

From the findings of the study, it appears that using the MR strategy in simulations with SPs has no advantage over using the $\mathrm{ABCDE}$ mnemonic in simulations with mannequins. There was no significant difference in the performance scores between the MR-SP group and the MM group in terms of assessing and managing patient deterioration. The use of MR-based interventions in simulation training has been shown to improve the performance of highly technical skills such as laparoscopic cholecystectomy and more complex skills such as patient deterioration management (Arora et al., 2011; Eldred-Evans et al., 2013; Ignacio et al., 2016). However, unlike previous studies, this study tried to compare the effects of the MR strategy with simulation using SPs and a conventional strategy with simulation using mannequins in assessing and managing patient deterioration. A randomized posttest was used for the comparison. The results did not corroborate the findings of 
enhanced performance that was evident in the previous studies.

The use of the ABCDE mnemonic combined with simulation using mannequin has been utilized to teach students on the management of deteriorating patients and has been demonstrated as effective in enhancing nursing students' performance when they are presented with a deteriorating simulated patient (Liaw, Rethans, Scherpbier, \& Klainin-Yobas, 2011a). The results of this present study suggest that there is no difference between the use of the ABCDE mnemonic with mannequin simulation and the use of the MR strategy with SP simulation in enhancing performance.

Meanwhile, the cohesiveness of the MR script included in the strategy results in an imagination effect that facilitates a better absorption of the learning material; in this instance, the assessment and management of patient deterioration (Ignacio et al., 2016; Leahy \& Sweller, 2008). Hence, it appears that MR has more benefits for long-term memory storage (Ignacio et al., 2016; Leahy \& Sweller, 2004, 2008). This reasoning is in line with the qualitative findings of this study that showed that the students found the use of MR useful as they were able to recall what they needed to do, especially because the script was presented in a story format which they were able to easily visualize. Furthermore, the MR script can be used independently without the other components of the strategy. The script can be used by the learners at their own convenience. Hence, there is no limit to the number of times one can practice. The participants generally felt that the more MR is used, the more likely it can improve performance.

One probable explanation for why there was no significant difference between the performance mean score of the participants in the MP-SP compared with the MM group was that the MR strategy was only given once. After the facilitated MR practice, the participants in the MR-SP group were encouraged to do use MR strategy (minus the SP simulation) on their own at their own convenience. Hence, during this time of independent practice, no feedback was given. MR solely relies on the recreation of the task from memory, resulting in a more developed mental representation of the task (Frank, Land, Popp, \& Schack, 2014); however, this may not translate to improved performance unless there is available feedback, which may not be present when one independently practices MR. Although MR can be practiced individually anytime and anywhere, it may be necessary to have any form of feedback after individual MR practice sessions. Feedback, when a post-MR simulation is not possible, can come from the video of the skill or from the presence of someone who could go through the steps with the trainee after his/her individual MR practice. It has been reported that the benefits of the MR strategy may prove to be self-limiting when performance feedback is unavailable (Driskell et al., 1994).

Aside from increasing the frequency of MR practice with feedback, future studies could measure the imagination effect MR has on individual participants. This is because MR technique relies on imagery that produces an imagination effect on the participants. As mentioned previously, when imagination effect results, there is better assimilation of knowledge and skill (Leahy \& Sweller, 2008). By quantifying this imagination effect, and correlating it with performance scores, the effectiveness of the MR strategy in improving performance can be captured, even for complex tasks such as assessment and management of clinical deterioration.

Some of the participants who were interviewed saw the MR strategy as a means to reflect on what went wrong during their actual clinical experience. After experiencing an actual clinical event, the students reflect and integrate new information into their MR practice so that they can improve for future experiences. As such, the strategy can also be linked with the principle of experiential learning, which is important in acquiring knowledge (Kolb, 1984). This learning principle can be valuable to both technical and nontechnical knowledge acquisition.

Both physiological and self-report stress measures did not show any difference between the MR-SP group and the MM group. MR has been noted to reduce stress and relieve anxiety (Arora et al., 2011; Cocks et al., 2014). This premise, however, was not supported by the results of this study. Both groups were assessed on performance for the posttest, and this could have mitigated the effects of the intervention on the MR-SP group's stress levels as any form of assessment is considered stressful and could potentially induce anxiousness (Marshall \& Jones, 2003). Nonetheless, the findings from the individual interviews suggest that the MR strategy facilitated stress reduction. The participants from both groups concurred that preparation is needed prior to exposure to critical clinical events. Technical competence, such as the ability to properly assess patients, and emotional competence, such as their ability to cope with stress, were seen as vital in managing deteriorating patients, in concordance with what has been mentioned in literature (Ignacio et al., 2016; LeBlanc, 2009; Liaw et al., 2012). Mental preparation was generally perceived as a means to be ready in anticipating patient deterioration, and a component of being mentally prepared is having done an MR of the critical event. Thus, MR prepares the students not only for the task at hand but also to be less stressed when managing an acute critical event (Ignacio et al., 2016).

\section{Limitations}

A pretest would be a useful component for the randomized design as it could determine which group had a significant improvement from the baseline to its posttest. This was not done to avoid the practice effect that would inevitably improve performance for both groups (Heiman, 2002). Also, as all the participants were familiar with the ABCDE mnemonic, the results of the participants in the MR-SP group may not have just resulted from the MR strategy. Thus, 
adding a third distinct intervention arm to the study may be of value. The SPs in deteriorating patient simulations were only used in training the MR-SP group but not the MM group. As the previous studies of this research team showed, SPs have benefits in deteriorating patient simulation training (Ignacio et al., 2015, 2016), both groups should have used SPs in patient deterioration simulations training. Such a design will attribute the results of the study solely to the MR strategy or to the ABCDE mnemonic without being confounded by the SP methodology. However, using mannequins in patient deterioration simulations has always been a component of the conventional strategy used in teaching students. A change to SPs will make the strategy unconventional. Finally, the individual MR strategy practice sessions and actual physical practice sessions of the participants should have been closely monitored and correlated with the results. These should be addressed in future studies. Moving forward, similar studies should also endeavor to measure the imagination effect that MR produces in the participants as this could be an indirect means of capturing its effectiveness, particularly in learning complex skills. Additionally, it would be valuable to measure the longterm effects of the MR strategy on clinical practice.

\section{Conclusion}

The use of a MR strategy with simulation using SPs was compared with the use of the ABCDE mnemonic with a mannequin simulation to teach final year nursing students about patient deterioration management. The quantitative measures of performance and stress were found to be not significant. On the other hand, the qualitative data from the individual interviews showed that the participants perceived that the MR strategy benefited them in their training and preparation for clinical practice. These findings suggest that the MR strategy cannot be easily dismissed as a possible adjunct to simulation in training health care professionals. It may be a viable strategy to improve performance and to decrease stress in health professions' training.

\section{Acknowledgments}

The authors would like to thank the staff of the Centre for Healthcare Simulation, National University of Singapore for their valuable support. There was no funding for this research study. No conflict of interest is declared by the authors.

\section{References}

Aoun, S. G., Batjer, H. H., Rezai, A. R., \& Bendok, B. R. (2011). Can neurosurgical skills be enhanced by mental rehearsal? World Neurosurgery, 76(3-4), 214-215.

Arora, S., Aggarwal, R., Moran, A., Sirimanna, P., Crochet, P., Darzi, A., ., \& Sevdalis, N. (2011). Mental practice: Effective stress management training for novice surgeons. Journal of the American College of Surgeons, 212(2), 225-233.

Braun, V., \& Clarke, V. (2006). Using thematic analysis in psychology. Qualitative Research in Psychology, 3(2), 77-101.

Cocks, M., Moulton, C. A., Luu, S., \& Cil, T. (2014). What surgeons can learn from athletes: Mental practice in sports and surgery. Journal of Surgical Education, 71(2), 262-269.

Driskell, J. E., Copper, C., \& Moran, A. (1994). Does mental practice enhance performance? Journal of Applied Psychology, 79, 481-492.

Eldred-Evans, D., Grange, P., Cheang, A., Yamamoto, H., Ayis, S., Mulla, M., ..., \& Reedy, G. (2013). Using the mind as a simulator: A randomised controlled trial of mental training. Journal of Surgical Education, 70(4), 544-551.

Frank, C., Land, W. M., Popp, C., \& Schack, T. (2014). Mental representation and mental practice: Experimental investigation on the functional links between motor memory and motor imagery. PLoS One, 9(4), e95175. http://dx.doi.org/10.1371/journal.pone.0095175.

Harvey, A., Nathens, A. B., Bandiera, G., \& LeBlanc, V. R. (2010). Threat and challenge: Cognitive appraisal and stress responses in simulated trauma resuscitations. Medical Education, 44(6), 587-594.

Heiman, G. W. (2002). Research methods in psychology (3rd ed.). Boston \& New York: Houghton Mifflin Company.

Hjemdahl, P. (2000). Cardiovascular system and stress. In Fink, G. (Ed.), Encyclopaedia of stress. San Diego, CA: Academic Press. (pp. 389-403).

Huang, C. J., Webb, H. E., Zourdos, M. C., \& Acevedo, E. O. (2013). Cardiovascular reactivity, stress, and physical activity. Frontiers in Physiology, 4, 314.

Ignacio, J., Dolmans, D., Scherpbier, A., Rethans, J. J., Chan, S. W. C., \& Liaw, S. Y. (2015). Comparison of standardised patients with highfidelity simulators for managing stress and improving performance in clinical deterioration: A mixed methods study. Nurse Education Today, 35(12), 1161-1168.

Ignacio, J., Dolmans, D., Scherpbier, A., Rethans, J. J., Lopez, V., \& Liaw, S. Y. (2016). Development, implementation and evaluation of a mental rehearsal strategy to improve clinical performance and reduce stress: A mixed methods study. Nurse Education Today, 37, 27-32.

Johnson, R., \& Onwuegbuzie, A. (2004). Mixed methods research: A research paradigm whose time has come. Educational Researcher, 33(7), 14-26.

Jones, L., \& Stuth, G. (1997). The uses of mental imagery in athletics: An overview. Applied and Preventive Psychology, 6, 101-115.

Kolb, D. A. (1984). Experiential learning: Experience as the source of learning and development. Englewood Cliffs, NJ: Prentice-Hall, Inc.

Leahy, W., \& Sweller, J. (2008). The imagination effect increases with an increased intrinsic cognitive load. Applied Cognitive Psychology, 22, 273-283.

Leahy, W., \& Sweller, J. (2004). Cognitive load and the imagination effect. Applied Cognitive Psychology, 18(7), 857-875.

LeBlanc, V. R. (2009). The effects of acute stress on performance: Implications for health professions education. Academic Medicine, 84(10 Suppl), S25-S33.

Liaw, S. Y., Chan, S., Scherpbier, A., Rethans, J. J., \& Pua, G. G. (2012). Recognising, responding and reporting patient deterioration: Transferring simulation learning to patient care settings. Resuscitation, 83, 395-398.

Liaw, S. Y., Rethans, J. J., Scherpbier, A., \& Klainin-Yobas, P. (2011a). Rescuing a patient in deteriorating situations (RAPIDS): A simulationbased educational program on recognising, responding and reporting of physiological signs of deterioration. Resuscitation, 82(9), 1224-1230.

Liaw, S. Y., Scherpbier, A., Klainin-Yobas, P., \& Rethans, J. J. (2011b). Rescuing a patient in deteriorating situations (RAPIDS): An evaluation tool for assessing simulation performance on clinical deterioration. Resuscitation, 82(11), 1434-1439.

Marshall, G., \& Jones, N. (2003). A pilot study into the anxiety induced by various assessment methods. Radiography, 9, 185-191.

Polit, D. F., \& Beck, C. T. (2006). Essentials of nursing research: Appraising evidence for nursing practice (8th ed.). Philadelphia, PA: Lippincott Williams \& Wilkins. 
Spielberg, C. D., Gorsuch, R. L., Lushene, R., Vagg, P. R., \& Jacobs, G. A. (1983). Manual for the state-trait anxiety inventory. Palo Alto, CA: Consulting Psychologists Press.

Vitasari, P., Wahab, M. N. A., Othman, A., Herawan, T., \& Sinnadurai, S. K. (2011). Re-test of state trait anxiety inventory (STAI) among engineering students in Malaysia: Reliability and validity tests. Procedia Social and Behavioral Sciences, 15, 3843 3848.

Wetzel, C. M., George, A., Hanna, G. B., Athanasiou, T., Black, S. A., Kneebone, R. L., ..., \& Woloshynowych, M. (2011). Stress management training for surgeons-A randomised, controlled, intervention study. Annals of Surgery, 253(3), 488-494. 